University of Nebraska - Lincoln

DigitalCommons@University of Nebraska - Lincoln

\title{
Continuous Arsine Detection Using a Peltier-Effect Cryogenic Trap To Selectively Trap Methylated Arsines
}

\author{
Guoying Chen \\ USDA-ARS, guoying.chen@ars.usda.gov \\ Bunhong Lai \\ USDA-ARS \\ Xuefei Mao \\ Chinese Academy of Agricultural Sciences \\ Tuanwei Chen \\ Fujian Agriculture and Forestry University \\ Miaomiao Chen \\ Jinan University
}

Follow this and additional works at: https://digitalcommons.unl.edu/usdaarsfacpub

Chen, Guoying; Lai, Bunhong; Mao, Xuefei; Chen, Tuanwei; and Chen, Miaomiao, "Continuous Arsine Detection Using a Peltier-Effect Cryogenic Trap To Selectively Trap Methylated Arsines" (2017).

Publications from USDA-ARS / UNL Faculty. 1770.

https://digitalcommons.unl.edu/usdaarsfacpub/1770

This Article is brought to you for free and open access by the U.S. Department of Agriculture: Agricultural Research Service, Lincoln, Nebraska at DigitalCommons@University of Nebraska - Lincoln. It has been accepted for inclusion in Publications from USDA-ARS / UNL Faculty by an authorized administrator of DigitalCommons@University of Nebraska - Lincoln. 


\title{
Continuous Arsine Detection Using a Peltier-Effect Cryogenic Trap To Selectively Trap Methylated Arsines
}

\author{
Guoying Chen, ${ }^{* \dagger}{ }^{\dagger}$ Bunhong Lai, ${ }^{\dagger}$ Xuefei Mao, ${ }^{\dagger}$ Tuanwei Chen, ${ }^{\S}$ and Miaomiao Chen $\|$
}

${ }^{\dagger}$ Agricultural Research Service, Eastern Regional Research Center, U.S. Department of Agriculture, 600 E. Mermaid Lane, Wyndmoor, Pennsylvania 19038, United States

${ }^{\ddagger}$ Institute of Quality Standard and Testing Technology for Agro-Products, Chinese Academy of Agricultural Sciences, 12 Zhongguancun S. Street, Beijing 100081, China

${ }^{\S}$ College of Food Science, Fujian Agriculture and Forestry University, Fuzhou, Fujian 350002, China

${ }^{\|}$Department of Food Science, Jinan University, Guangzhou, Guangdong 510632, China

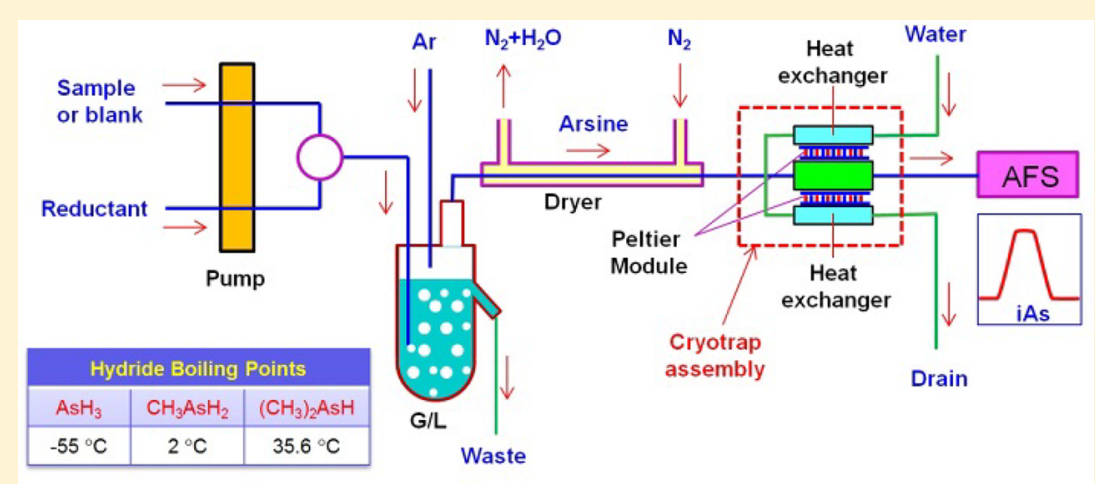

ABSTRACT: Hydride generation (HG) is an effective technique that eliminates interfering matrix species and enables hydride separation. Arsenic speciation analysis can be fulfilled by cryogenic trapping (CT) based on boiling points of resulting arsines using liquid nitrogen $\left(\mathrm{LN}_{2}\right)$ as a coolant. In this work, $\mathrm{LN}_{2}$ was replaced by the thermoelectric effect using a cryogenic trap that consisted of a polytetrafluoroethylene (PTFE) body sandwiched by two Peltier modules. After the trap was precooled, the arsines flew along a zigzag channel in the body and reached a sorbent bed of $0.2 \mathrm{~g}$ of $15 \%$ OV-3 on Chromosorb W-AW-DMCS imbedded near the exit of the trap. $\mathrm{CH}_{3} \mathrm{AsH}_{2}$ and $\left(\mathrm{CH}_{3}\right)_{2} \mathrm{AsH}$ were trapped, while $\mathrm{AsH}_{3}$, that passed the trap unaffected, was detected by atomic fluorescence spectrometry. Continuous operation led to enhanced throughput. For inorganic As, the limit of detection (LOD) was $1.1 \mathrm{ng} / \mathrm{g}$ and recovery was $101.0 \pm 1.1 \%$. Monomethylarsonic acid and dimethylarsinic acid did not interfere with $0.2 \pm 1.2 \%$ and $-0.3 \pm 0.5 \%$ recoveries, respectively.

$\mathrm{H}$ ydride generation (HG), first demonstrated by Marsh in $1836,{ }^{1}$ allows thorough separation of volatile arsines from interfering matrix components using a simple gas/liquid separator $(\mathrm{G} / \mathrm{L})$. HG is especially useful for separation of arsines of toxicologically relevant arsenic species (TRAS): inorganic As (iAs), monomethylarsonic acid (MMA), and dimethylarsinic acid (DMA). For elements that form volatile hydrides, HG dramatically enhances sensitivity leading to extensive implemention in atomic absorption spectrometry, ${ }^{2}$ atomic fluorescence spectrometry (AFS), ${ }^{3,4}$ inductively coupled plasma (ICP)-optical emission spectrometry, ${ }^{5}$ and ICP-mass spectrometry. ${ }^{6}$

Arsenic speciation analysis can be carried out either prior to or post HG. Schemes of pre-HG speciation analysis include high performance liquid chromatography (HPLC), solid phase extraction $(\mathrm{SPE}),^{7}$ and dispersive liquid-liquid microextraction. ${ }^{8}$ HG of TRAS could be performed under a set of conditions specifically tuned to favor iAs, leading to selective iAs quantitation without HPLC. ${ }^{9}$ Alternatively, HG could be carried out under 4 sets of conditions. ${ }^{10}$ For each set, a linear equation was set up to correlate AFS intensity to TRAS concentrations where coefficients were slopes of TRAS calibration curves. TRAS concentrations in unknown samples were then solved mathematically.

Cryogenic trapping $(\mathrm{CT})^{11,12}$ and focusing $(\mathrm{CF})^{13,14}$ are effective post-HG speciation schemes based on boiling points (BPs) of resulting arsine species: $-55,2$, and $35.6{ }^{\circ} \mathrm{C}$ for $\mathrm{AsH}_{3}$, $\mathrm{CH}_{3} \mathrm{AsH}_{2}$, and $\left(\mathrm{CH}_{3}\right)_{2} \mathrm{AsH}$, respectively. The arsines of TRAS are first trapped in a U-tube immersed in liquid nitrogen $\left(\mathrm{LN}_{2}\right)$. When condensation is complete, the U-tube is exposed to the ambient air or heated by a nichrome coil. Rising temperature causes trapped arsines to be released from the U-tube in the order of ascending BPs; the arsines are then swept by a carrier gas stream to an As specific detector. CT separates arsines of

Received: July 6, 2017

Accepted: August 10, 2017

Published: August 10, 2017 
TRAS without using chemical reagents leading to low cost and green chemistry. Thus far, $\mathrm{LN}_{2}$ was used in all cases as a coolant. Though effective, $\mathrm{LN}_{2}$ can be hazardous if safety procedures are not followed. In this work, $\mathrm{LN}_{2}$ was replaced by a pair of solid-state Peltier modules to promote personnel safety. Such a thermoelectric cryotrap is described in this manuscript for the first time including its design and operation for iAs quantification in rice.

Arsenic is a notoriously toxic environmental contaminant. Unlike workers in As-related mining and manufacturing industries, the general public is exposed to As mainly from drinking water and rice. ${ }^{15}$ Low-dose chronic intake adversely affects human health ${ }^{16}$ and may cause cancer in all organs. ${ }^{17}$ The International Agency for Research on Cancer identified As as a Group 1 human carcinogen. On the other hand, rice is the top energy source $(20 \%)$ for humans and the dietary staple for half of world population. However, rice accumulates much more As in comparison to other terrestrial crops, in part due to anaerobic growing conditions. ${ }^{18}$ Among TRAS, iAs is more toxic than MMA and DMA and far more toxic than other organic arsenic species commonly found in seafood such as arsenobetaine and arsenocholine. ${ }^{19,20}$ The Food and Agriculture Organization/World Health Organization determined 3.0 $\mu \mathrm{g} / \mathrm{kgbw} \cdot \mathrm{d}$ as iAs to be the lower limit on the benchmark dose for a $0.5 \%$ increased incidence of lung cancer $\left(\mathrm{BMDL}_{0.5}\right){ }^{21}$ Currently, China has set a $200 \mathrm{ng} / \mathrm{g}$ iAs maximum level (ML) in rice; the Codex Committee on Contaminants in Foods proposed 200 and $300 \mathrm{ng} / \mathrm{g}$ draft iAs MLs in polished and raw rice, respectively. ${ }^{22}$ To meet regulatory requirements and protect consumers, sensitive iAs detection methods are much needed. Rice was selected as the model matrix due to its unique ability to accumulate As and its important role in human diet.

\section{EXPERIMENTAL SECTION}

Reagents and Solutions. As ${ }^{\mathrm{III}}$ standard solution (1000 $\mu \mathrm{g} / \mathrm{L}$ in $1-5 \% \mathrm{HNO}_{3}$ ) was purchased from Fluka (Milwaukee, WI, USA); $\mathrm{As}^{\mathrm{V}}$ standard solution $\left(1000 \mu \mathrm{g} / \mathrm{L}\right.$ in $\left.\leq 2.5 \% \mathrm{HNO}_{3}\right)$ was from PerkinElmer (Waltham, MA, USA). Solid MMA $(\geq 99.5 \%)$ and DMA $(\geq 99.0 \%)$ were purchased from Chem Service (West Chester, PA, USA) and Sigma-Aldrich (Milwaukee, WI, USA), respectively. MMA and DMA stock standard solutions were individually made by dissolving an accurate amount of the respective solid in $10 \mathrm{~mL}$ of deionized water (DIW); further dilution was done in DIW. $\mathrm{NaBH}_{4}$ (>99\%), 30\% silicon antifoam solution, ACS grade KI, $\mathrm{HNO}_{3}$, and L-ascorbic acid were from Sigma-Aldrich. ACS grade $\mathrm{HCl}$ and $\mathrm{NaOH}$ were from Mallinckrodt (Phillipsburgh, NJ, USA). Rice flour $1568 \mathrm{~b}$ standard reference material (SRM) was purchased from National Institute of Standard and Technologies (NIST, Gaithersburg, MD, USA). The sorbent used in the cryotrap, $15 \%$ OV-3 on Chromosorb W-AWDMCS 60/80, was purchased from Ohio Valley Specialty Company (Marietta, OH, USA).

A $0.28 \mathrm{~N}$ nitric acid digestion solution was prepared by diluting $4.45 \mathrm{~mL}$ of concentrated nitric acid in $100 \mathrm{~mL}$ of DIW in a $250 \mathrm{~mL}$ volumetric flask and filling to volume. A prereduction solution, also used as the reagent blank, was prepared by dissolving $300 \mathrm{~mL}$ of concentrated $\mathrm{HCl}, 40 \mathrm{~g}$ of $\mathrm{KI}$, $4 \mathrm{~g}$ of $\mathrm{L}$-ascorbic acid, and $1 \mathrm{~mL}$ of $30 \%$ silicone antifoam in 0.5 $\mathrm{L}$ of DIW and then diluting to $1 \mathrm{~L}$. A $1 \%(\mathrm{w} / \mathrm{v}) \mathrm{NaBH}_{4}-0.1 \mathrm{M}$ $\mathrm{NaOH}$ reduction solution was prepared daily by dissolving $10 \mathrm{~g}$ of $\mathrm{NaBH}_{4}$ and $4 \mathrm{~g}$ of $\mathrm{NaOH}$ in DIW, diluting to $1 \mathrm{~L}$, and filtering through a $0.45 \mu \mathrm{m}$ Supor-450 membrane filter (Pall
Life Sciences, Port Washington, NY, USA) under vacuum and stored in a container with a loose cap. DIW prepared with a Barnstead E-pure system (Dubuque, IA, USA) was used to prepare all the solutions.

Cryogenic Trap Design. Shown in Figure 1 is the cryotrap assembly. At the core is a trap body made of polytetrafluoro-

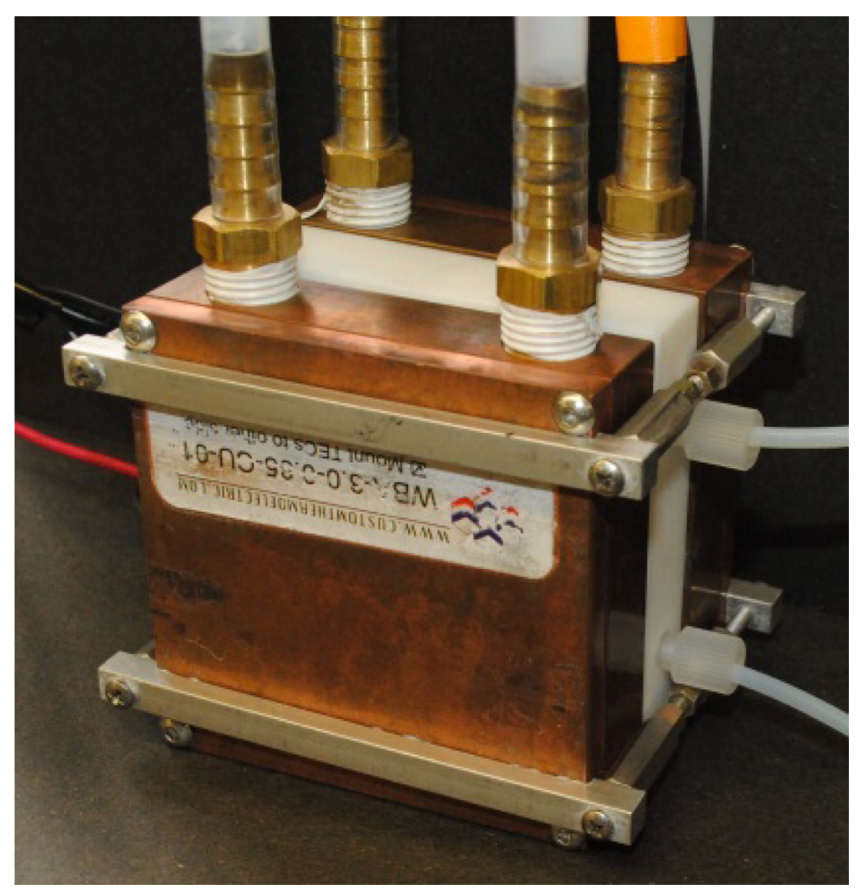

Figure 1. Cryogenic trap assembly.

ethylene (PTFE) with $75 \times 75 \times 19 \mathrm{~mm}$ outer dimensions (Figure 2). The central portion of the body was $9 \mathrm{~mm}$ thick

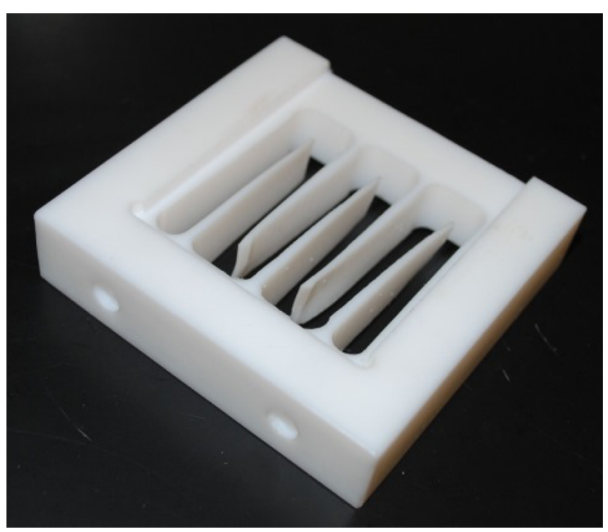

Figure 2. PTFE cryotrap body.

through which a $6.35 \mathrm{~mm}$ wide zigzag flow channel was cut. The channel had a cross section of $57 \mathrm{~mm}^{2}$ and a total length of $282 \mathrm{~mm}$ leading to a total volume of $16 \mathrm{~mL}$. The body was sandwiched by two $50 \times 50 \mathrm{~mm}$ Peltier modules (Model 19911-5M31-12CW-S, Custom Thermoelectric, Bishopville, $\mathrm{MD}, \mathrm{USA}$ ) with cold plates facing the trap body. The modules, each rated at $23.8 \mathrm{~V}$ and $12 \mathrm{~A}$, were connected in parallel and powered by a variable power supply (Model HY3050EX, Acifica, San Jose, CA, USA). Installed near the exit of the channel was a bed of $0.2 \mathrm{~g}$ of Chromosorb sorbent with two sides held by the PTFE channel walls and two sides by the 


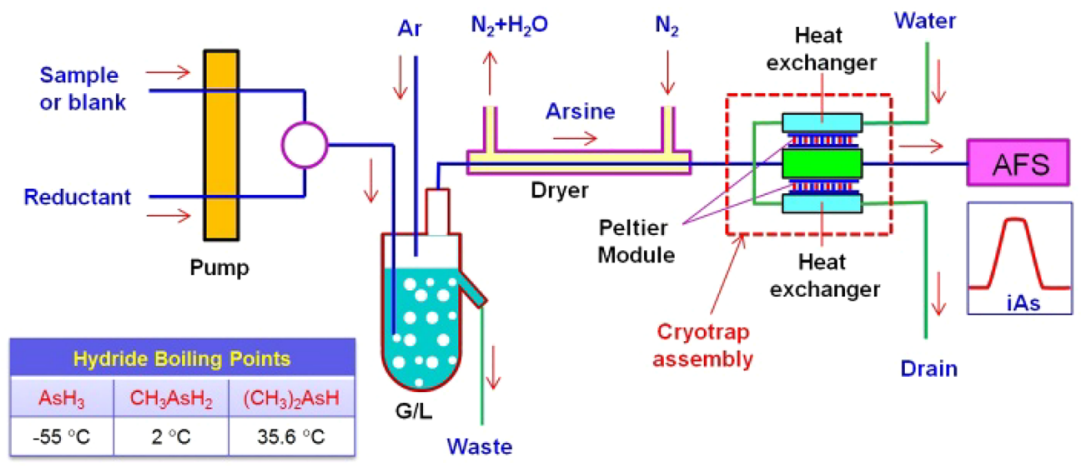

Figure 3. Schematic diagram of the HG-CT-AFS system.

ceramic cold plates, and the remaining sides facing the flow and the exit, respectively, were confined by glass wool. Apiezon M vacuum grease (Apiezon Products, Manchester, UK) was applied on edges of the trap body to maintain airtightness.

Hot plates of the modules were in contact with two waterblock heat exchangers (Model WBA-3.0-0.85-CU-01, Custom Thermoelectric). Arctic Silver 5 thermal compound (Arctic Silver, Visalia, CA, USA) was applied to hot plate-water block interfaces to promote heat conduction. The heat exchangers, of a copper shell design, were circulated with $15{ }^{\circ} \mathrm{C}$ water from a thermostatic bath (Model ESRB-7, Techne, Staffordshire, UK).

Microwave-Assisted Digestion. Rice samples were purchased from local markets. A $10 \mathrm{~g}$ aliquot was ground using a small coffee mill (Model F203, Krups, Millville, NJ, USA); the resulting rice flour was kept in a desiccator before use. Aliquots of $250 \pm 5 \mathrm{mg}$ of rice flour were weighed into 100 $\mathrm{mL}$ PTFE vessels, to which $10 \mathrm{~mL}$ of $0.28 \mathrm{~N}$ nitric acid was added, followed by brief shaking. The vessels were then placed in a 14-position carousel of a Mars 5 microwave digestion system (CEM, Matthews, NC, USA). The temperature program consisted of a $2 \mathrm{~min}$ ramp to $95{ }^{\circ} \mathrm{C}$ and $30 \mathrm{~min}$ hold at this temperature. When samples cooled down to room temperature, the contents were transferred to $15 \mathrm{~mL}$ centrifuge tubes, followed by centrifugation at $3600 \mathrm{~g}$ for $5 \mathrm{~min}$.

Hydride Generation. Supernatants $(2 \mathrm{~mL})$ were transferred to $10 \mathrm{~mL}$ volumetric flasks which were filled to the mark with the prereduction solution. The flasks were then capped; the contents were mixed by hand shaking and then allowed to stand for $1 \mathrm{~h}$ for complete reduction. $\mathrm{As}^{\mathrm{III}}-\mathrm{NaBH}_{4}$ reaction was carried out in flow injection mode. ${ }^{7}$ The resulting arsines were swept by argon carrier gas at $250 \mathrm{~mL} / \mathrm{min}$ flow rate through a 48 in. long Nafion dryer (MD-110-48P, Perma-Pure, Farmingdale, NJ, USA) where most of the moisture permeated through a Nafion tubing wall into a counter-flowing nitrogen stream.

Cryogenic Trapping. As shown in Figure 3, the cryotrap was integrated into a Millennium Excalibur atomic fluorescence spectrometer (P S Analytical, Kent, UK) between the dryer and the detector. Prior to sample injection, the trap was precooled with the water bath set at $15{ }^{\circ} \mathrm{C}$ and the Peltier modules were powered at $10.0 \mathrm{~V}$. Once trap temperature stabilized at $40 \mathrm{~min}$, the trap was run in continuous cooling mode. At the end of the work shift, the cryotrap was powered off while dry argon continued to flow for $1 \mathrm{~h}$ to release trapped arsines from the cryotrap into an exhaust suction pipe.

Atomic Fluorescence Spectrometry. In the detection chamber of the Excalibur spectrometer, $\mathrm{AsH}_{3}$ was atomized by a diffusion flame supported by hydrogen gas evolved from
$\mathrm{NaBH}_{4}$ acidification. The resulting atomic cloud was excited by a boosted discharge arsenic hollow cathode lamp (Model E033L001, Photron, Victoria, Australia); the resonance emission at $193.7 \mathrm{~nm}$ was collected at $90^{\circ}$, isolated by an interference emission filter, and detected by a solar blind photomultiplier tube. AFS operation was controlled by Millennium software ( $P S$ Analytical) under the same conditions as previously described.

Rice Analysis. A standard curve was constructed daily using As ${ }^{\text {III }}$ reagent standards. Rice samples were analyzed in triplicates; quantitation was based on peak height. NIST $1568 \mathrm{~b}$ rice flour CRM was used for method validation.

\section{RESULTS AND DISCUSSION}

Peltier-Effect Cryotrap vs $\mathbf{L N}_{2}$ Coolant. CT as a physical approach fulfills separation of volatile hydrides based on BPs without using chemical reagents. The resulting method is thus safe, cost-effective, and environmentally friendly. Traditional cryotrap designs include a quartz U-trap $(6 \mathrm{~mm}$ od $\times 200 \mathrm{~mm}$ 1), ${ }^{23}$ a Pyrex U-tube $(6 \mathrm{~mm}$ od $\times 400 \mathrm{~mm})$ half packed with $60-80$ mesh glass beads, ${ }^{24}$ a PTFE tubing $(3 \mathrm{~mm}$ id $\times 200 \mathrm{~mm}$ $1),{ }^{25}$ a glass U-tube $(6 \mathrm{~mm}$ od $\times 150 \mathrm{~mm} \mathrm{l})$ packed with silanized glass wool, ${ }^{12}$ a glass U-tube $(6 \mathrm{~mm}$ od $\times 160 \mathrm{~mm} \mathrm{l})$ packed with glass wool treated with dimethyl-dichlorosilane plus a PTFE chromatographic column $(4000 \mathrm{~mm} 1 \times 3.5 \mathrm{~mm}$ d) packed with Supelco Carbopack B HT 100 sorbent 40/60, ${ }^{14}$ and a glass tube $(2.5 \mathrm{~mm}$ id $\times 305 \mathrm{~mm} \mathrm{l})$ filled with $0.8 \mathrm{~g} 15 \%$ OV-3 on Chromosorb W-AW-DMCS 45/60 and wrapped with $15-20 \Omega \mathrm{Ni} 80 / \mathrm{Cr} 20$ wire $(0.51 \mathrm{~mm}$ diameter at $5.275 \Omega$ / $\mathrm{m}) .{ }^{4,26}$ In the last two cases, sorbent was used to introduce gas chromatography (GC). Such an approach, known as CF, sharpens analyte peaks resulting in improved resolution and accuracy. In all cases, the cryotraps were immersed in a $\mathrm{LN}_{2}$ bath. An icy water or alcohol bath may be used for precooling.

$\mathrm{LN}_{2}$ is an excellent coolant with an extremely low BP $\left(-195.8^{\circ} \mathrm{C}\right)$. Such extreme temperature can cause cold burns to skin and eye upon brief contact. Furthermore, large liquid-togas expansion ratio $\left(1: 694\right.$ at $\left.20{ }^{\circ} \mathrm{C}\right)$ of this coolant poses potential hazards due to asphyxiation, pressure buildup, or explosion. In this work, $\mathrm{LN}_{2}$ was replaced by two Peltier modules; CT was carried out by thermoelectric effect, also known as Peltier effect. A pair of solid-state devices operated at low voltage was easier to handle and much safer than $\mathrm{LN}_{2}$. With $\mathrm{LN}_{2}$ eliminated, so was the need to frequently replenish coolant.

The limitation of a Peltier module is the maximum temperature difference between hot and cold plates, of $\sim 62$ ${ }^{\circ} \mathrm{C}$ in theory (without load) and far less than $62^{\circ} \mathrm{C}$ in practice 
Table 1. Comparison of iAs-in-Rice Results by the SPE-HG-AFS vs HG-CT-AFS Method

\begin{tabular}{|c|c|c|c|c|}
\hline rice samples & country origin & SPE-HG-AFS（ng/g） & HG-CT-AFS (ng/g) & difference, $\%$ \\
\hline med grain & USA & $74 \pm 2$ & $72 \pm 1$ & -2.7 \\
\hline jasmine & Thailand & $77 \pm 1$ & $73 \pm 1$ & -5.3 \\
\hline glutinous & USA & $66 \pm 2$ & $67 \pm 1$ & +1.5 \\
\hline enriched long-grain & USA & $74 \pm 1$ & $72 \pm 0$ & -2.7 \\
\hline brown med-grain & USA & $94 \pm 1$ & $90 \pm 2$ & -4.3 \\
\hline basmati & India & $60 \pm 3$ & $51 \pm 1$ & -16 \\
\hline matta & India & $49 \pm 2$ & $52 \pm 2$ & +5.9 \\
\hline jasmine & Vietnam & $66 \pm 2$ & $76 \pm 1$ & +14 \\
\hline brown basmati & India & $235 \pm 9$ & $242 \pm 5$ & +3.8 \\
\hline ponni & India & $57 \pm 2$ & $64 \pm 5$ & +15 \\
\hline organic haiga med-grain & USA & $83 \pm 5$ & $80 \pm 1$ & -3.7 \\
\hline organic basmati & India & $46 \pm 1$ & $50 \pm 2$ & +8.3 \\
\hline wild red & Thailand & $86 \pm 5$ & $93 \pm 3$ & +7.8 \\
\hline wild black & USA & $45 \pm 1$ & $48 \pm 0$ & +6.5 \\
\hline mixed rice flour & & $68 \pm 3$ & $70 \pm 2$ & +5.8 \\
\hline NIST SRM 1568b@92 \pm 10 & USA & $102 \pm 5$ & $92 \pm 4$ & +0.0 \\
\hline
\end{tabular}

(with load). As a result, it is impossible to condense $\mathrm{AsH}_{3}$ (BP at $-55{ }^{\circ} \mathrm{C}$ ) using single-stage Peltier modules and roomtemperature cooling water. However, a single-stage trap can completely retain $\mathrm{CH}_{3} \mathrm{AsH}_{2}\left(\mathrm{BP}\right.$ at $\left.2{ }^{\circ} \mathrm{C}\right),\left(\mathrm{CH}_{3}\right)_{2} \mathrm{AsH}(\mathrm{BP}$ at $\left.35.6{ }^{\circ} \mathrm{C}\right)$, and $\left(\mathrm{CH}_{3}\right)_{3} \mathrm{As}\left(\mathrm{BP}\right.$ at $\left.56{ }^{\circ} \mathrm{C}\right)$. Due to higher toxicity, iAs is usually the only target of interest in most analysis, vide supra. Unlike $\mathrm{LN}_{2}$ that is used in disruptive cooling-heating cycles, this cryotrap retained only methylated arsines allowing continuous detection of $\mathrm{AsH}_{3}$. Consequently, sample throughput was enhanced.

Cryogenic Trap Material. CT or CF poses certain requirements on the material and design of the trap body: resistance to arsine corrosion and ideally no irreversible adsorption. Metals excel in thermal conductivity; copper $(\mathrm{Cu})$ is an example with $k_{\mathrm{Cu}}=401 \mathrm{~W} / \mathrm{mK}$. However, $\mathrm{Cu}$ reacts with arsine $\mathrm{e}^{27}$ disqualifying it as trap material. Though chemical resistance can be improved by a layer of gold coating, adsorption of arsine on the gold surface poses another technical obstacle. $^{28}$ Graphite excels in thermal conductivity and machinability, but it also suffers from arsine adsorption. ${ }^{29}$ On the other hand, hardness of many ceramic materials renders machining highly difficult.

In comparison, polymers are adequate in chemical inertness yet less prone to irreversible adsorption. Among polymers, PTFE possesses superior chemical resistance and machinability, but the limited surface area of the PTFE gas channel plus the exposed surfaces of ceramic cold plates resulted in a small capacity to adsorb and condense methylated arsines. A sorbent bed was thus installed ${ }^{26}$ to increase surface area and introduce adsorption in addition to condensation, a physical process. The extremely low thermal conductivity $(0.25 \mathrm{~W} / \mathrm{mK})$ of PTFE made it a poor construction material for a trap body under rapid cooling-heating cycles but an excellent insulator when the trap was operated in a continuous cooling mode.

Use of Adsorbent. CT in a continuous mode necessitates a trap capacity large enough to sustain adsorption of $\mathrm{CH}_{3} \mathrm{AsH}_{2}$ and $\left(\mathrm{CH}_{3}\right)_{2} \mathrm{AsH}$ long enough without breakthrough. In this work, $0.2 \mathrm{~g}$ of $15 \%$ OV-3 on Chromosorb W-AW-DMCS 60/ 80 served this purpose. The sorbent also enabled GC leading to better resolved peaks of released methylated arsines. ${ }^{4,26} \mathrm{GC}$ was not exploited in this work due to the fact that the only target, $\mathrm{AsH}_{3}$, was slightly polar with a low $\left(-55^{\circ} \mathrm{C}\right) \mathrm{BP}$; hence, it did not condense or adsorb on the sorbent. The sorbent capacity was tested by repeated injection of $8.9 \mathrm{ng} / \mathrm{g}$ MMA 16 times plus $67.2 \mathrm{ng} / \mathrm{g}$ DMA 10 times which, based on a $200 \times$ dilution factor, was equivalent to 200 injections for a rice sample containing $140 \mathrm{ng} / \mathrm{g}$ MMA and $670 \mathrm{ng} / \mathrm{g}$ DMA, much higher than those in typical rice. No breakthrough was observed. For an 8-h work shift, this corresponded to 25 injections per hour. At the end of the shift, the cryotrap was flushed with argon for $1 \mathrm{~h}$ to release trapped arsines and to renew the trap. In practice, continuous operation mode not only enhances throughput but also maintains the integrity of the Peltier modules. It was observed that repeated cooling-heating cycles caused stress leading to microcracks on the cold ceramic plates which shortened module life and posed the hazard of toxic arsine leakage.

Cryotrap Performance. The hydride yields were found to depend on the concentration of $\mathrm{HCl}$ in the reductant solution; $^{30}$ the yield from DMA using $30 \% \mathrm{HCl}$ was only about $40 \%$ of those from $\mathrm{As}^{\mathrm{III}}$ and $\mathrm{As}^{\mathrm{V}}$. Among the resulting arsine species, significant (19\%) loss of $\left(\mathrm{CH}_{3}\right)_{2} \mathrm{AsH}$ and total loss of $\left(\mathrm{CH}_{3}\right)_{3}$ As were previously reported through a $12 \mathrm{in}$. Nafion dryer (MD-110-12FP, PermaPure) at a $90 \mathrm{~mL} / \mathrm{min}$ combined $\left(\mathrm{He}+\mathrm{H}_{2}\right)$ flow rate. ${ }^{31} \mathrm{AsH}_{3}$ and $\mathrm{CH}_{3} \mathrm{AsH}_{2}$, on the contrary, experienced no loss. In this work, a $50 \%$ loss was estimated for $\left(\mathrm{CH}_{3}\right)_{2} \mathrm{AsH}$ through a 48 in. dryer made of the same tubing at $250 \mathrm{~mL} / \mathrm{min}$ Ar flow rate. A longer dryer was necessary in this work to better exclude moisture; otherwise, ice would gradually build up and finally clog the trap.

When the trap temperature stabilized at the end of the 40 min precooling period, recovery study was carried out using a mixed rice sample from 5 common rice types. ${ }^{7}$ Low recoveries, $0.2 \pm 1.3 \%$ for MMA at $186 \mathrm{ng} / \mathrm{g}$ and $-0.3 \pm 0.5 \%$ for DMA at $440 \mathrm{ng} / \mathrm{g}$, implied that $\mathrm{CH}_{3} \mathrm{AsH}_{2}$ and the portion of $\left(\mathrm{CH}_{3}\right)_{2} \mathrm{AsH}$ that survived the dryer were effectively retained by the sorbent bed inside the cryotrap. Quantitative (101.0 \pm $1.1 \%$ ) recovery for iAs at $100 \mathrm{ng} / \mathrm{g}$, on the other hand, revealed $\mathrm{AsH}_{3}$ was not trapped due to its low $\left(-55^{\circ} \mathrm{C}\right) \mathrm{BP}$. When HG was initiated, the temperature of the cryotrap interior was maintained at around $-3{ }^{\circ} \mathrm{C}$, measured using a HSTC-TT-J24S-36 thermocouple and a CN16PT-330 reader (Omega Engineering, Norwalk, CT, USA) on a similar PTFE cryotrap assembly under otherwise the same conditions. Under this temperature, total retention was expected for $\mathrm{CH}_{3} \mathrm{AsH}_{2}$, $\left(\mathrm{CH}_{3}\right)_{2} \mathrm{AsH}$, and $\left(\mathrm{CH}_{3}\right)_{3}$ As due to their higher BPs. Retention 
became incomplete when bath temperature was set at $20{ }^{\circ} \mathrm{C}$. The Peltier modules were powered only by $10 \mathrm{~V}$. A higher voltage would enhance cooling ability, but the heat dissipated to the heat exchangers would overwhelm the water bath thermostat leading to instability.

Determination of iAs in Rice. Adequate linearity $(R>$ 0.999) was always observed in daily As ${ }^{\mathrm{III}}$ calibration curves. The limit of detection (LOD), $1.1 \mathrm{ng} / \mathrm{g}$, was calculated $(3 \sigma)$ from 10 peak heights of reagent blanks. Validation was performed with NIST 1568b rice flour SRM. Excellent agreement (Table 1) was found between the result $(92 \pm 4 \mathrm{ng} / \mathrm{g})$ and certified iAs value $(92 \pm 10 \mathrm{ng} / \mathrm{g})$. Table 1 also shows the results of 15 rice samples measured by SPE-HG-AFS ${ }^{7}$ vs HG-CT-AFS. Close agreement was usually the case except for three samples with $>10 \%$ difference.

\section{CONCLUSIONS}

Design of a Peltier-effect cryotrap is presented here for the first time. Selective trapping of $\mathrm{CH}_{3} \mathrm{AsH}_{2}$ and $\left(\mathrm{CH}_{3}\right)_{2} \mathrm{AsH}$ on a Chromosorb sorbent bed enabled rapid determination of untrapped $\mathrm{AsH}_{3}$ with high sensitivity and reproducibility. In contrast to pre-HG speciation, this unique physical method obviated chemical separation and eliminated chemical reagents, therefore gaining simplicity, cost, green chemistry, and safety advantages. Continuous operation also enhanced sample throughput.

\section{AUTHOR INFORMATION}

\section{Corresponding Author}

*Phone: +1 215233 6495. Fax: +1 215233 6642. E-mail: guoying.chen@ars.usda.gov.

\section{ORCID}

Guoying Chen: 0000-0001-9532-0696

Notes

The authors declare no competing financial interest.

\section{ACKNOWLEDGMENTS}

M.C. is grateful for the financial support from Jinan University Guangzhou, China. Mention of trade names or commercial products in this Article is solely for the purpose of providing specific information and does not imply recommendation or endorsement by the U.S. Department of Agriculture (USDA). USDA is an equal opportunity employer.

\section{REFERENCES}

(1) Marsh, J. Edinburgh Philos. J. 1836, 21, 229-236.

(2) Narsito; Agterdenbos, J. Anal. Chim. Acta 1987, 197, 315-321.

(3) Simon, S.; Tran, H.; Pannier, F.; Potin-Gautier, M. J. Chromatogr. A 2004, 1024, 105-113.

(4) Musil, S.; Matoušek, T.; Currier, J. M.; Stýblo, M.; Dědina, J. Anal. Chem. 2014, 86, 10422-10428.

(5) Müller, J. Fresenius' J. Anal. Chem. 1999, 363, 572-576.

(6) Nakazato, T.; Tao, H. Anal. Chem. 2006, 78, 1665-1672.

(7) Chen, G.; Chen, T. Talanta 2014, 119, 202-206.

(8) Lai, G.; Chen, G.; Chen, T. Food Chem. 2016, 190, 158-163.

(9) Musil, S.; Pétursdóttir, Á. H.; Raab, A.; Gunnlaugsdóttir, H.; Krupp, E.; Feldmann, J. Anal. Chem. 2014, 86, 993-999.

(10) Cava-Montesinos, P.; Nilles, K.; Cervera, M. L.; Guardia, M. d. I. Talanta 2005, 66, 895-901.

(11) Braman, R. S.; Foreback, C. C. Science 1973, 182, 1247-1249.

(12) Andreae, M. O. Anal. Chem. 1977, 49, 820-823.

(13) Del Razo, L. M.; Styblo, M.; Cullen, W. R.; Thomas, D. J. Toxicol. Appl. Pharmacol. 2001, 174, 282-293.
(14) Cutter, L. S.; Cutter, G. A.; San Diego-McGlone, M. L. C. Anal. Chem. 1991, 63, 1138-1142.

(15) Khan, N.; Owens, G.; Bruce, D.; Naidu, R. Environ. Geochem. Health 2009, 31, 143-166.

(16) Naujokas, M. F.; Anderson, B.; Ahsan, H.; Aposhian, H. V.; Graziano, J. H.; Thompson, C.; Suk, W. A. Environ. Health Perspect. 2013, 121, 295-302.

(17) Bhattacharjee, P.; Chatterjee, D.; Singh, K. K.; Giri, A. K. Int. J. Hyg. Environ. Health 2013, 216, 574-586.

(18) Bhattacharya, P.; Welch, A. H.; Stollenwerk, K. G.; McLaughlin, M. J.; Bundschuh, J.; Panaullah, G. Sci. Total Environ. 2007, 379, 109120.

(19) Hughes, M. F. Toxicol. Lett. 2002, 133, 1-16.

(20) Gebel, T. W. Int. J. Hyg. Environ. Health 2001, 203, 249-262.

(21) WHO. Technical Report Series 959, Evaluation of Certain Food Additives and Cantaminants, 72nd Report of the Joint FAO/WHO Expert Committee on Food Additives; WHO: Geneva, Switzerland, 2010.

(22) FAO/WHO. Proposed Draft Maximum Levels for Arsenic in Rice (at Step 3); 2012; ftp://ftp.fao.org/codex/meetings/cccf/cccf6/cf06 08e.pdf. Accessed 30 June 2017.

(23) Braman, R. S.; Johnson, D. L.; Foreback, C. C.; Ammons, J. M.; Bricker, J. L. Anal. Chem. 1977, 49, 621-625.

(24) Crecelius, E. A. Anal. Chem. 1978, 50, 826-827.

(25) Burguera, M.; Burguera, J. L.; Brunetto, M. R.; de la Guardia, M.; Salvador, A. Anal. Chim. Acta 1992, 261, 105-113.

(26) Matoušek, T.; Hernández-Zavala, A.; Svoboda, M.; Langrová, L.; Adair, B. M.; Drobná, Z.; Thomas, D. J.; Stýblo, M.; Dědina, J. Spectrochim. Acta, Part B 2008, 63, 396-406.

(27) Quinn, R.; Dahl, T. A.; Diamond, B. W.; Toseland, B. A. Ind. Eng. Chem. Res. 2006, 45, 6272-6278.

(28) Chung, Y. S.; Evans, K.; Glaunsinger, W. Appl. Surf. Sci. 1998, $125,65-72$.

(29) Haacke, G.; Brinen, J. S.; Burkhard, H. J. Electrochem. Soc. 1988, $135,715-718$.

(30) Le, X.-C.; Cullen, W. R.; Reimer, K. J. Anal. Chim. Acta 1994, 285, 277-285.

(31) Taurkova, P.; Svoboda, M.; Musil, S.; Matousek, T. J. Anal. At. Spectrom. 2011, 26, 220-223. 